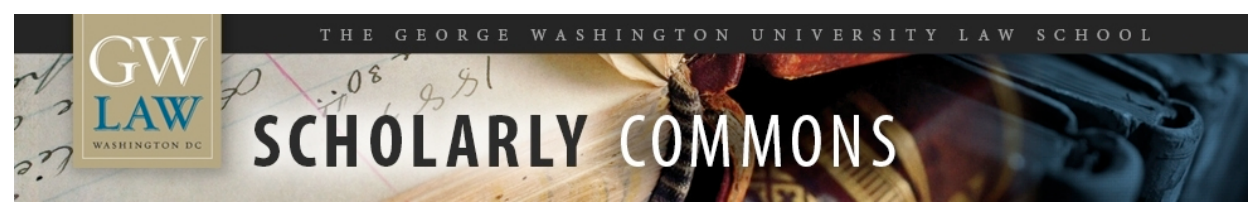

\title{
Getting Real About Abuse and Alienation: A Critique of Drozd and Olesen's Decision Tree
}

Joan S. Meier

George Washington University Law School, jmeier@law.gwu.edu

Follow this and additional works at: https://scholarship.law.gwu.edu/faculty_publications

Part of the Law Commons

\section{Recommended Citation}

Joan S. Meier, Getting Real About Abuse and Alienation: A Critique of Drozd and Olesen's Decision Tree, 7 J. Child Custody 219 (2010).

This Article is brought to you for free and open access by the Faculty Scholarship at Scholarly Commons. It has been accepted for inclusion in GW Law Faculty Publications \& Other Works by an authorized administrator of Scholarly Commons. For more information, please contact spagel@law.gwu.edu. 


\title{
Getting Real About Abuse and Alienation: A Critique of Drozd and Olesen's Decision Tree
}

\author{
JOAN S. MEIER \\ George Washington University Law School, Washington, D.C.
}

Specialists in abuse and alienation bave long taken opposing positions on the legitimacy of the concept of alienation in custody cases where abuse is alleged. One increasingly popular response that appears to carve a middle path is the acknowledgement that both alienation and abuse may co-exist, and a focus on "bybrid" cases, that is, those in which there are cross-allegations of abuse and alienation. This article discusses and critiques, from the perspective of an expert on abuse, one of the earliest and most significant approaches to the bybrid case: Drozd and Olesen's "Decision Tree." The author concludes that, while the decision tree is a thoughtful and well-intentioned effort to objectively and fairly assess abuse and alienation as well as other potential causes of a damaged child-parent relationship, the "bybrid" approacb and some of the Tree's concepts, such as "counter-productive protective parent," implicitly privilege alienation over abuse, and unintentionally, but inevitably, contribute to the marginalizing or biding of credible abuse and risk to children. Jobnston's credible empirical research demonstrates that child alienation occurs in only a small fraction of cases where parents engage in alienating bebavior and is almost always caused, at least in part, by the disfavored parent's bebaviors. Alienation, bowever, has been widely used to defeat legitimate and credible abuse concerns. The article concludes that alienation has been vastly over-emphasized in family

I am grateful to George Washington University Law School for its support of this article through a summer writing stipend. I am also appreciative of authors Drozd and Olesen's graciousness in welcoming this critique of their article. This article is dedicated to the many heroic mothers I have worked with who battled against the odds to protect their children in the face of tragic failures of the legal system.

Address correspondence to Joan S. Meier, J.D., Professor of Clinical Law and Director, Domestic Violence Legal Empowerment and Appeals Project, George Washington University Law School, 2000 G St. N.W., Washington, D.C. 20052, USA. E-mail: jmeier@law.gwu.edu 
courts and in the literature, in part because it furthers family courts' desire to maximize fathers' role in separating families. The article ends with an alternative and simpler 7-step proposal for assessment of alienation in "bybrid" cases, which is premised on the assumption that "true" alienation must be de-linked from the presence of abuse allegations and can only legitimately be evaluated after abuse bas been screened out.

KEYWORDS alienation, domestic violence, keywords abuse

Nothing is more polarized in the family law field than the debate over domestic abuse and parental alienation. Attention to domestic violence began to expand in the 1980s, as public policy and legal practice responded to the growing recognition of the prevalence and severity of domestic violence and its impact on children. Approximately a decade later, partly in response to the new attention to abuse, the theory of parental alienation ${ }^{1}$ - which focuses on the possibility that mothers' ${ }^{2}$ claims of abuse are a means of "alienating" the children from their noncustodial fatherbegan to influence family courts, rapidly becoming the dominant focus of custody evaluations and judicial decision-making. Because parental alienation theory encourages skepticism toward abuse allegations against fathers, and focuses instead on purported misconduct by the custodial parent (usually the mother), the two concepts are often pitted against each other both in and out of court. Indeed, they are often identified with the opposing political movements that have popularized their use: feminism and women's rights on the one hand, and "fathers' rights, "3 on the other (Adams, 2006; Stark, 2009).

In Is it Abuse, Alienation, and/or Estrangement? A Decision Tree, Leslie Drozd and Nancy Olesen (2004) tackle the unenviable challenge of weaving a neutral path between these highly polarized fields in order to "assist evaluators in identifying the causes of multiple allegations of maltreatment and abuse" (p. 66). The basic premise of their analysis is that abuse, alienation, and a number of other terms that they propose (e.g., "estrangement" and "counter-productive protective parenting") are all real and possible problems in families battling over custody and that custody evaluators need to be able to objectively consider multiple theories, using "multivariate thinking" rather than the either/or approach of those who fall clearly on one side of the alienation/abuse divide. To aid in this mission, they set out a "decision tree" to assist evaluators in assessing all the possibilities and avoiding "confirmatory bias" or "dichotomous thinking" (Drozd \& Olesen, p. 69).

However admirable Drozd and Olesen's mission, it is this paper's premise that the decision tree is ultimately misguided. It might be appropriate to carve out a middle path if parental alienation had been recognized by 
courts or other proponents of the concept as a significant phenomenon independent of its use as a means of defeating abuse claims. However, even a cursory look at the etiology and application of alienation theory indicates that its current significance is inseparable from its utility as a means of discrediting claims of abuse. Moreover, as the following discussion suggests, alienation's focus on the parent-child relationship is intrinsically incompatible with the focus on safety and risk called for when dealing with abuse. Treating parental alienation as an equivalent concern to abuse in custody-litigating families thus inherently devalues abuse allegations, while over-valuing a claim that is most often used to deflect responsibility for abuse. It simply is not possible or appropriate to seek a middle ground between reality and denial, which is the hallmark of many cases with competing abuse and alienation claims.

The remainder of this article summarizes the decision tree model and theory, and offers some specific critiques focused on how the treatment of alienation claims as comparable to abuse claims inevitably undermines the credibility of true abuse claims and tilts evaluators and courts against protective and abused parents. I see this analysis as extending beyond the particulars of the Drozd and Olesen decision tree: some of the pitfalls of their approach are inherent to the alienation "project." Indeed, since publication of the decision tree, the concept of "hybrid" (i.e., involving cross-allegations of abuse and alienation) cases has gained substantial attention in the field (Fidler \& Bala, 2010; Friedlander \& Walters, 2010). Thus, the discussion herein should also be relevant to the approach taken by many custody evaluators and researchers who propound the ideal of "multivariate" assessments of alienation and other factors, including abuse (Gould, 2006; Kelly and Johnston, 2001; Johnston, 2005). The article concludes with what I consider to be a more realistic and modest formulation for weighing valid alienation concerns in custody adjudications involving abuse, and provides a much simpler proposed protocol for evaluators and courts assessing competing abuse and alienation claims.

\section{THE DECISION TREE}

The fundamental goal of Drozd and Olesen's (2004) decision tree article is to provide:

a model for how to deal with competing cross-allegations, such as allegations of abuse and alienation. When there are allegations and counter-allegations of abuse and alienation, it is particularly important to have a conceptual framework to organize the multiple hypotheses as data is gathered. A conceptual framework lays out an array of variables to consider, and can help guard against premature closure of analysis and the narrow consideration of alternatives due to emotional polarization or dichotomous thinking. (pp. 68-69) 
The decision tree requires the evaluator to evaluate "three overarching hypotheses, which are non-mutually exclusive alternatives" to explain why a child "may not have positive relationships with both parents." The three hypotheses are (1) normal developmental variations; (2) poor parenting (on the part of one or both parents, including possible alienating behavior); and (3) abuse (including child abuse, substance abuse, and/or domestic violence) (Drozd \& Olesen, p. 70, Table 1). To "test the various hypotheses" the evaluator must investigate each one "independently and fully" (Drozd \& Olesen, p. 72). The authors emphasize that "each one of the hypotheses should be tested before drawing any conclusions as to the cause of a child's rejection of a parent" (Drozd \& Olesen, p. 73).

As implied previously, application of the decision tree process is triggered solely by a finding that the child's relationship with one parent is impaired. The first step on the tree is to determine if the child has "basically positive" relationships with both parents and if the child's behaviors are age and stage appropriate. If so, then "current risk is low" and, it is implied, no further alienation evaluation is necessary (Drozd \& Olesen, 2004, pp. 69-70). If, however, the child's relationship with a parent is impaired and/or her behaviors are not age/stage appropriate, then the evaluator should proceed through the decision tree, beginning with the "Safety First" evaluation, and then moving through the three hypotheses for why a child's relationship with a parent may be impaired. Notably, this trajectory means that the "safety" or abuse assessment is not called for, unless there is a relationship problem. ${ }^{4}$

In discussing safety, the article seems to suggest that its consideration is most likely needed when there are previous legal findings of abuse (Drozd \& Olesen, 2004, p. 71). When an evaluator has independent reasons to believe a safety assessment is necessary, the article suggests that evaluators must report such suspicions to Child Protection, and that a further assessment by the evaluator (or other experts in abuse) will be called for only if the court orders it (Drozd \& Olesen, p. 72). The discussion of safety ends with the following: "Once the issue of the child's safety is evaluated, we move back to the decision tree to ask, 'Why?" " Again, the discussion that follows makes clear that the question refers to the impaired parent-child relationship.

In answering "why," the tree requires assessment of the three hypotheses. In essence, the "developmental" hypothesis posits that children sometimes have different levels of bonding to their parents for reasons having to do with "affinity" (shared styles and/or interests), "alignment" with one parent (which is responsive to parental conflict but not caused by a parent), or situational alignments which develop in the course of divorce or for other reasons (Drozd \& Olesen, 2004, pp. 74-75). The "Poor Parenting" hypothesis includes both poor parenting by either parent (e.g., absence, neglect, laxity, or over-rigidity), and alienating behavior by the aligned parent (Drozd \& Olesen, p. 75). The authors emphasize the importance of assessing specific alienating behaviors by the parent and "symptoms" of alienation of the child 
(Drozd \& Olesen, p. 77), as well as assessing the degree of severity of alienation both by the parent and as expressed by the child. They further discuss the difference between intentional and unintentional (more responsive to correction) behaviors by the aligned parent and the relative insignificance of "transient" disparagement, which is fairly common among divorcing parents (Drozd \& Olesen, p. 79). They also note that both parents may contribute to a child's alienation, for example, when the father is emotionally cold and disconnected, and the mother disparages him to the child.

The third hypothesis, the "Abuse Hypothesis," requires evaluators to conduct an "abuse-sensitive evaluation," including using appropriate questions, respecting the need for safety in interviews, and incorporating a robust understanding of the role and effects of abuse in families (Drozd \& Olesen, 2004, pp. 81-85). The authors emphasize the importance of assessing parents' fears of the other and a broad definition of abuse including psychological, sexual, financial, and legal (Drozd \& Olesen, p. 84). They also devote a number of pages to assessing variables which "mediate" the effects of abuse on the child, including the child's own persona and resilience, the parenting styles of each parent, the "sabotaging" behavior of the aggressive parent, and the protectiveness (including both successful and "counter-productive" protective parenting) of the non-aggressor parent (Drozd \& Olesen, pp. 86-92). They further urge evaluators to go beyond simple "up" or "down" findings of abuse, to provide a nuanced discussion of "how abuse, if present, has operated in a particular family and what steps are necessary to move the family towards greater health" (Drozd \& Olesen, p. 85).

After discussing each of the aforementioned summarized "hypotheses," the authors reiterate the importance of multivariate thinking and thorough investigation of relevant factors and emphasize that "[a]lienation and abuse [emphasis in original] are not dichotomous variables; instead, they may occur across continua" (Drozd \& Olesen, 2004, p. 101). They also urge further research on "the prevalence and degree of co-occurrence of abuse... alienation, estrangement, sabotaging, and counter-productive protective parenting in divorcing families" (Drozd \& Olesen, p. 101).

\section{CRITIQUE}

Drozd and Olesen's bona fides and good intentions are undeniable. In addition, the decision tree offers the appearance of objectivity and comprehensiveness, including some attention to safety and abuse concerns. Yet, embedded in its structure and assumptions are implicit dismissals of abuse and safety concerns in favor of alienation concerns. The net result is that abuse allegations are demoted in importance while alienation allegations are inappropriately elevated. Moreover, by failing to clearly acknowledge that alienation allegations are often, if not most often, used by abusers to 
refute abuse claims (Jaffe, Crooks, \& Bala, 2009; Meier, 2009a), ${ }^{5}$ and by treating alienation allegations as equivalent in import and credibility to abuse allegations, the endeavor as a whole unintentionally assists in obscuring genuine abuse and reinforces courts' dismissals of mothers seeking to protect their children and themselves.

This critique is not one that can be met by tweaking or revising the decision tree in specific ways. Rather, the critique flows from the very nature of the project: In this author's view, treating alienation claims on a par with abuse claims in the same cases inevitably results in the discounting or marginalization of abuse and its consequences for the family. In my view, consistent (ironically) with Richard Gardner's own definition of Parental Alienation Syndrome (see n. 1), alienation is only a valid consideration where abuse has been ruled out.

\section{THE ENTIRE ANALYSIS IS FRAMED BY ALIENATION CONCERNS, RESULTING IN MARGINALIZATION OF ABUSE/SAFETY CONCERNS}

The emphasis on alienation of a child from a parent-rather than the risks presented by that parent-pervades the decision tree.

The Abuse Evaluation is Predicated on Relationship or Behavior Problems, not Abuse Allegations

According to the decision tree, the very first question the evaluator is to ask (in a case by definition containing abuse allegations) is not "Is the child at risk?" but rather, "Does the child have basically positive relationships with both parents?" (Drozd \& Olesen, 2004, p. 70). If so, and if the child's behaviors are age and stage appropriate, the evaluation, apparently, ends. Indeed, the "Safety First" assessment is triggered only if the answer to the relationship or behavior question is "no." 6

From the perspective of the domestic violence field, this is a stunningly peculiar way to structure an evaluation where abuse has been alleged. The implication that safety must be assessed only if the relationship is impaired is strange at best. Many families where abuse occurs do not evidence obvious impairment of the parent-child relationships or obvious child behavior problems. Particularly in cases of child sexual abuse, children often split off the abusive experience and live a surface "normal" relationship with their abuser, sometimes even compensating for the abuse by excelling in school or other activities (Gelles \& Conte, 1990; Kendall-Tackett, Williams, \& Finkelhor, 1993). The suggestion that safety concerns only exist if a relationship is impaired, even where abuse bas been alleged, is either naive about abuse, a quiet minimization of the credibility of abuse allegations, or, more 
likely, a reflection of the authors' primary focus on relationship over abuse concerns. In fact, the contrast between this article and Drozd, Kuehnle, \& Walker's (2004) earlier "Safety First" article 7 suggests that the mere presence of alienation allegations tilts the analysis away from focusing on abuse and safety first and foremost. In this respect, this article itself recapitulates the common dynamics in custody litigation in which, once alienation is alleged, abuse allegations become merely a reason to explore alienation, and the focus on safety concerns is lost.

Second, if abuse is real, it is critically important to the custody determination, regardless of whether the parent-child relationship is impaired or the child's behaviors are problematic. As Drozd and Olesen know (Drozd et al., 2004, pp. 83-88), abuse of a mother ${ }^{8}$ is inherently detrimental to children in the home. Men who abuse their wives often have parenting styles that are psychologically if not physically destructive for children, including rigid gender roles, subordinating children's interests and needs to the needs of their own egos, using the children to demean the mother, and so forth (Bancroft \& Silverman, 2002). And it is widely recognized that $30-60 \%$ of children in homes where an adult is abused are also abused by an adult, most commonly, the perpetrator of the adult abuse (Drozd et al., 2004; Edleson, 1999;). Finally, risks to children go up-not down-when an abuser separates from his adult victim (Hart, 1992; Mahoney, 1991). Thus, as of 2008, 45 states mandated that their custody courts consider domestic abuse when it is alleged; 25 have established a presumption against custody to an abuser (American Bar Association Commission on Domestic Violence, 2008).

There can thus be no question that, as an ethical and legal matter, if abuse is alleged in custody litigation, it should be thoroughly assessed. Indeed, the American Psychological Association's (APA) Guidelines for Custody Evaluators specifically urge evaluators to have expertise in abuse where such allegations are part of a case - or to retain outside consultants with that expertise (APA, 1994, 2009). Drozd herself has elsewhere acknowledged this: "When an evaluator who is without expertise in the assessment of domestic violence allegations is asked to do such ... it is imperative that the evaluator refer that portion of the case to a colleague who has expertise..." (Drozd et al., 2004, p. 79). It is thus difficult to understand why this article and the decision tree do not straightforwardly recommend that abuse and safety be assessed whenever abuse allegations are raised in custody litigation. The failure to do so contributes to the marginalization of abuse concerns. ${ }^{9}$

\section{The Failure to Evaluate Abuse First Taints the Entire Process}

While Drozd and Olesen suggest that the three hypotheses for why a child has a problematic relationship with a parent (abuse, alienation, and/or estrangement) can be evaluated in any order, and that if anything, the abuse hypothesis should be evaluated first (Drozd \& Olesen, 2004, p. 75), they 
present the hypotheses in the opposite order. By failing to require abuse to be evaluated first, the decision tree analysis begins on the wrong foot.

Precisely because the alienation theory is predicated on the assumption that abuse allegations are invalid, where abuse is alleged an objective evaluator must evaluate the abuse claims first. "Once domestic violence has been identified as an issue, it should provide a context for assessing other information, such as communication patterns between the partners..." (Jaffe et al., 2009, p. 178). Since, as Drozd, Olesen, and other psychologists in the field have noted, abuse may well explain any alienation or "estrangement" the child feels from a parent, it would seem essential to evaluate the abuse before reaching the alienation question (Drozd \& Olesen, 2004). If abuse is real, then alienation, at least by the protective parent, according to Gardner, as well as even Drozd \& Olesen, is not an issue (Drozd \& Olesen, 2004; Gardner, 2006). Nor should it be an issue, because, as is generally acknowledged, a child's rejection of an abusive parent is a natural, healthy response to a parent's aggression, not an unhealthy result of a manipulative parent's maltreatment.

Evaluating abuse first is essential for another reason as well: Leading custody and abuse evaluator Peter Jaffe (Jaffe et al., 2009, p. 179) urges that family courts put cases involving abuse allegations on an "off-ramp" from the usual family court process, so as to ensure adequate evaluation of abuse before the family is "carried along" the "freeway" to co-parenting, the assumed goal of family courts for non-violent families (see also Stark, 2009). Some kind of "off-ramp" is necessary because family courts are structured to ensure maximum father-child access post separation, but in families where the father abuses the mother, "[t]here is no evidence that children benefit in the longer term from having regular face to face contact with a violent parent and considerable suggestive evidence that the real and potential harms to children of being exposed to domestic violence or other forms of abuse of their mother outweighs any harms experienced by not seeing an abusive parent" (Stark, 2009, p. 289).

When the decision tree begins, therefore, by evaluating the child's relationships with the parents, rather than with the credibility of the abuse concerns, it tilts the evaluation from the start. Once an evaluation has identified a child's hostility toward a parent (whether named "estrangement" or "alienation"), and has assessed the degree to which the protective parent has contributed to that alienation, a subsequent finding of abuse by the disfavored parent is inevitably overshadowed by the finding of alienation and attribution of that alienation to the non-abusive parent. In fact, this very failure to first require a serious assessment of abuse-despite the Parental Alienation Syndrome (PAS) theory's foundational requirement that abuse allegations must be false for a positive diagnosis of PAS-was the reason PAS was widely recognized as conclusory or circular (Hoult, 2006). Unfortunately, by also failing to require abuse to be seriously assessed first, the decision tree 
process implicitly (if inadvertently) facilitates a similar misuse of alienation claims to turn the tables on those who allege abuse and the mislabeling of such parties as emotional abusers, that is, alienators. ${ }^{10}$ At best, this dynamic establishes abuse and alienation as equals, that is, both as forms of abuse. At worst, it actually fuels a focus on purported alienation over and above any actual abuse.

It is worth noting that the equation of alienation and abuse as comparably harmful is unsupported by empirical knowledge. There is no scientific basis for treating purported alienation-particularly where it consists simply of a mother's claims the children are at risk and her feelings of fear or distress, which may affect the children-as "emotional abuse." Indeed, leading alienation researchers acknowledge that there is not yet any scientific evidence that even intentional alienating conduct causes long-term harm to children (Johnston \& Kelly, 2004, p. 84). On the contrary, long-term research has found that child alienation toward one parent typically resolves itself over time as children mature and they are able to develop a more objective view of and relationship with that parent (Wallerstein, Lewis, \& Blakeslee, 2000). There is, however, ample and largely undisputed evidence that domestic violence and, certainly, child abuse have long-term harmful effects on children, and that children are potentially traumatized by exposure to the abuse of their mother (Drozd et al., 2004; Jaffe \& Geffner, 1998, pp. 374 et seq.). Thus, a leading scholar and forensic expert states: "No other problem encountered by evaluators is comparable to battering in its prevalence, duration, scope, effects on personhood, and...significance for children's current well-being or future prospects." (Stark, 2009, 288-89).

\section{The Crediting of Alienation Claims Inherently Discredits} Abuse Claims

One reason the polarization between "abuse" and "alienation" scholars and advocates is so entrenched is that alienation claims emerged and were given significant attention in the courts only after alienation became a means of denying abuse. In the past, as described elsewhere (Meier, 2009a), when battered mothers have told judges about the ways the abuser was turning the children against them, or calling them "whore" and "slut" and other abusive derogatory terms in front of the children, judges (and evaluators) evidenced little, if any, concern. Even now, empirically, as Drozd and Olesen (2004) and other alienation researchers (e.g., Johnston, 2005) note, it is battering men, far more than mothers, who typically seek to "alienate" their children from the other parent (Drozd \& Olesen, p. 94). Bancroft and Silverman (2002) comprehensively documented the intention and ability of many battering fathers to undermine the mother's relationship and authority with her children. Yet, the alienation theory which now pervades custody courts does not reflect this prevalent reality; rather, it embodies the notion that mothers 
alleging abuse are presumptive alienators. Given that derogatory behavior by one parent toward the other has historically been virtually ignored in custody and visitation determinations, it cannot be a coincidence that alienation-understood as a reason to reject abuse claims-is now becoming the determinative focus of evaluations and court decisions (Meier, 2009a).

The fact that alienation claims are commonly used to deny abuse-and that they regularly succeed in turning credible abuse allegations against the messenger-is reflected in the following examples, which are just a few examples of the hundreds of cases, both published and unpublished, reported to service providers every year:

A child writes a letter (in therapy) to her father saying "I wish you would stop touching me in my privates. Stop doing that because it hurts! Why didn't you stop when I told you to stop?" Medical evidence concerning the girl's sister (a co-victim) is indicative of sexual abuse. The police believe the girls' descriptions of sexual abuse. Nonetheless, a court-appointed mental health expert describes this as a "textbook" case of PAS, recommends removal of the children from their mother, and then only supervised visitation. After the supervised visitation center director reports that the mother told her daughters on the phone that she loved them, the court eliminates all contact (even by phone) for four years (Lesher \& Neustein, 2005, pp. 173-176).

A 5 year old child reports to her mother that her father touched her vagina "for a long time... just using his fingers..." that it made her feel "uncomfortable" and she didn't like it. The father has been emotionally abusive and threatening to the mother in the past. The mother is advised by child protection to report to the police and the child's pediatrician. The police, child protection social worker, and a nationally recognized child abuse expert from Yale believe the child's reports of sexual abuse (which she repeats in their interviews with her). The father is prosecuted criminally, resulting in a hung jury and no conviction. The mother is subsequently found by evaluators (without interviewing the child or the treating providers) to be committing parental alienation because she believes the child and does not dissuade the child from her beliefs or feelings toward her father. The court adopts these findings and orders the child removed from her mother's care and put into foster care with relatives. Subsequently, the low income mother is fined over $\$ 3$ million damages for "malicious" prosecution of the father. The father voluntarily terminates his parental rights. (Record in $M D v . A B, 2008$ ).

A professional woman is married for 30 years to a professional man who is emotionally abusive to her and extremely controlling. She has been the children's primary caretaker, organizing her professional work around her caretaking needs. As the relationship is falling apart, he strangles and violently rapes her. In the custody litigation the children are not 
hostile to their father, but do not want shared physical custody and one does not want to visit him regularly. The evaluator accuses the mother of parental alienation, based on her allegations of abuse and rejection of joint custody, and recommends shared custody as necessary to reduce further alienation. The court dismisses the rape allegation (and detailed testimony) as a figment of the mother's imagination and imposes joint legal and physical custody (Record in $L v, L, 2002$ ).

A couple divorces after a marriage marked by a "pattern of severe abuse" (as found by the court). Subsequently, the 2-and then 4-year-old child accuses her father of putting a "stick in my butt-butt" and "poo-poo" (child's word for vagina). Children's Hospital and County social workers, as well as the child's therapist, suspect sexual abuse and urge the mother to get legal protection for the child. After a trial, including an opinion by the court's forensic evaluator that "allegations like this are common in high conflict divorces," and suggesting that parental alienation may be at work, the court concludes that the mother is not coaching the child, but the child is fabricating these allegations, possibly because, among other things, she "senses her mother's dislike" for her father. He finds no sexual abuse and orders unsupervised visits to continue (Wilkins $v$. Ferguson, 2007) (appellate court reversing trial court).

A woman is abused periodically by her husband, who is also abusive to his young sons, hitting and yelling at them, and raging about their mother to them. After she flees with the boys to England, later returning after the filing of parental kidnapping charges, the custody evaluator describes her conduct as "shameless alienation." The son's complaints about his father's treatment are pointed to as further evidence of the mother's alienation. Despite the court's findings of two past incidents of domestic violence, the court switches custody to the father based on the alienation finding, and then-after the child credibly reports yet another incident of paternal abuse, this time substantiated by child protection-ends all further visitation with the mother. Subsequently, the court refuses to return the children to the mother despite (i) the temporary removal of the children from the father after one child's call to 911 reporting fear that his father would kill him in his sleep, and the father's being visibly under the influence when the police responded, and (ii) the father's arrest and felony charges for felony child endangerment from extremely reckless driving and evasion of arrest with the children in the truck (Record in O v. O, 2008-2009).

In light of the growing epidemic of cases like these, ${ }^{12}$ it is hard not to believe that alienation claims and the attention they receive are taken seriously precisely because they are useful to rebut or at least discount abuse claims. In addition, of course, that is precisely how they are frequently used in custody litigation, to the profound detriment of children. In short, by privileging alienation theory, courts are empowering abusers' denial and 
causing untold suffering for children. A growing number of parents report that their reporting of child or adult abuse to the family court was used against them and resulted in complete loss of custody, as well as sometimes restricted or terminated visitation (Petition in Accordance with InterAmerican Commission on Human Rights, 2007).

What can an objective researcher/evaluator do about this kind of misuse of the alienation concept, short of renouncing the concept altogether? A good faith and in-depth understanding of the manipulation and distortion alienation claims effectuate in abuse cases should lead to a commitment to ensure that alienation is not misused in this way. One way to ensure this would be to forthrightly acknowledge the dubious history and misuse of the alienation theory and then to explore ways to cabin alienation's use in court to reduce its misuse to defeat credible abuse claims. In addition to ensuring careful assessment of abuse before considering alienation, we should consider limiting the definition of what constitutes alienation so that good faith protective actions cannot be re-framed as alienation. This approach would mean that petitions for protection or taking a child for evaluation or therapy, all of which are routinely pointed to as sinister forms of alienation, could not be considered evidence of "alienating behaviors." Such accusations have been absurdly successful in discrediting genuinely protective mothers' efforts to keep their children and themselves safe. ${ }^{13}$

Another avenue for cabining alienation's damaging misuse would be to limit consideration of alienation to instances where there is an independent basis for claiming alienation other than the other parent's allegations of abuse and actions consistent with those allegations, or to cases where abuse has been completely ruled out. (These proposals are amplified in the following sections.) Drozd and Olesen (2004) do not offer any of these suggestions. Instead, by treating abuse and alienation as equally concerning, in the same cases, they unavoidably lend weight to the incorrect assumption that many abuse claims are potentially nothing more than alienating tactics.

\section{SAFETY AND ABUSE CONCERNS ARE MARGINALIZED}

\section{"Safety First" Assessment is Inappropriately Limited}

As seems implicit in the "Safety First" moniker, if abuse is an issue, it should be incumbent on courts, and therefore evaluators, to ensure that the litigation process and the evaluation process, does not put anyone at risk. While Drozd and Olesen (2004), to their credit, do talk about safety, they limit their call for a "safety assessment" to the relatively rare cases where a court has already made a finding of abuse or has specifically ordered a safety evaluation (pp. 71-72). This is far too narrow a population of cases; as noted previously, abuse and safety should be assessed in every case with abuse allegations. 
Moreover, it is not clear whether the "Safety First" assessment is intended to actually assess future risk: Both this article and the earlier "Safety First" article narrowly focus on asking if a child is "currently safe..." and call for assessment of "immediate factors" affecting safety (Drozd et al., 2004, p. 71). By using the term "immediate safety" the authors imply that the issue is immediate safety during the litigation and not long-term safety after determination of custody/visitation. This implication is reinforced in the decision tree article by the separation of the discussion of "the Abuse hypothesis" from the initial "safety" discussion. Here, the decision tree treats abuse questions as relating only to a child's alienation from the parent and does not link that analysis to the earlier discussion of "safety." If, as it appears to do, the decision tree intends to de-link the analysis of allegations of past abuse from the assessment of the child's current or future safety in unsupervised contact with the allegedly abusive parent, it is mistaken. Evaluating past abuse is essential to-indeed, many would say it is the only means of assessing future safety. No accurate future assessment is possible without the determination of what happened in the past (Bancroft \& Silverman, 2002). Again, if all allegations of past abuse were thoroughly evaluated first, both the safety and relationship questions could be answered next.

Even where Abuse is Found, the Tree Calls for Assessment of Parenting, Alienation, Estrangement, and so Forth

Oddly, once safety is evaluated, the evaluation then moves back to the decision tree to assess "why" the parent-child relationship is impaired (Drozd \& Olesen, 2004, p. 71). But, if the safety evaluation results in a finding that safety is at issue, there should be no need to go further in evaluating reasons for the child's estrangement. Moreover, "safety first" should also mean that safety is a required predicate for rebuilding the relationship. Thus, further assessment of alienation (or "estrangement" in abuse cases) should be subordinated to recommendations regarding safety, yet the article makes no such suggestion.

Similar to this cabining of the "safety" assessment, the "Abuse Hypothesis" frames merely one of three possible answers to the question of why a child is disaffected from a parent. It thus appears that in Drozd and Olesen's (2004) conception, the assessment of abuse and even of safety/danger, does not dislodge the overarching focus on parent-child relationships. Indeed, it is implicit in this process that even a finding of danger to the child does not negate the imperative to consider the child-parent relationship and, presumably, to further the potentially dangerous parent's access.

To those who specialize in domestic violence and child abuse, this too is both peculiar and troubling. From an abuse perspective, once one parent is found to present a cognizable risk of physical, sexual, or significant emotional abuse to a child, the custody/visitation decision should flow from that core 
reality (Jaffe et al., 2009; Stark, 2009). Child protection and child safety (and arguably adult victims' safety), should dominate the custody/visitation determination once a safety risk has been identified (Drozd et al., 2004). If one parent presents a risk to a child, and the other does not, so long as the non-abusive parent is fit and bonded with the child, the custody determination should be, in fact, relatively obvious (Dalton, Carbon, \& Olesen, 2003).

While it is true that visitation, even in abuse cases, may still be in a child's best interests if safety can be assured (Bancroft $\&$ Silverman, 2002), the decision tree neither specifically distinguishes between custody and visitation, nor does it even narrow its focus to visitation upon identification of abuse. In fact, the decision tree goes further and encourages evaluators to continue to evaluate each parents' parenting skills, styles, and degree of bonding with the child, as well as a myriad of other factors. In so doing, the tree moves the focus away from a "child protective" focus and back to a comparative parenting focus. This, too, contributes to a discounting of abuse and its consequences.

It is rare that any evaluation of any mother's ${ }^{14}$ parenting will fail to find any flaws. This is even more likely to be true for mothers who have been abused, or are trying to protect a child from abuse. However, evaluators' assessments of parents' personae and parenting behaviors are often also skewed by the failure to take into account a history of abuse. For instance, too often an "abuse victim who attempts to limit contact with an abuser may be deemed hostile and unfriendly, and punished for her protestations and hypervigilance" (Jaffe \& Crooks, 2005, p. 2). Abuse victims who are angry and attempt to control case outcomes may be perceived as having narcissistic personality disorder or other pathologies ${ }^{15}$ (Smith \& Coukos, 1997). Additionally, evaluators and courts "often find batterers to be sympathetic and convincing in their denials, [however] these credibility assessments are often incorrect" (Bancroft \& Silverman, 2002, p. 124; Meier, 2003, p. 690). Moreover, "[m]ost batterers present with no obvious mental health problems. In comparison, many victims suffer from a variety of trauma symptoms related to their abuse" (Jaffe \& Crooks, 2005). The tendency of custody evaluators to over-rely on psychological tests that are not normed for custody litigation and fail to accurately assess for or identify abusive relationships has been compellingly described in the literature (Bancroft \& Silverman, 2002; Bowermaster, 2002; Emery, Otto, \& O'Donohue, 2005; Jaffe, Lemon, \& Poisson, 2003). Such tests are notorious for over-pathologizing battered women and qualifying batterers as better adjusted than the victimized mother (Bancroft \& Silverman, 2002; Dalton, Drozd, \& Wong, 2006; Jaffe, Lemon et al., 2003). For all these reasons, custody evaluations that fail to appropriately weigh domestic violence often favor the perpetrator of abuse.

In this context, the net effect of treating abuse as on a par with other parenting skills and styles is to invite an erroneous discounting of abuse. It is implicit in the decision to proceed with an evaluation of alienation and other parenting issues, that such findings could outweigh the abuse or 
possibly even explain or justify it. If not, why bother? But, if abuse is not pre-emptive of the other questions of parenting skill and bonding, it becomes, at best, demoted to simply one of an array of "parenting skills" (or lack thereof), and at worst, ignored. Indeed, (as noted in the following sections) the decision tree offers no guidance on how all these differing findings should be weighed against each other, leaving it wide open for evaluators to discount abuse and risk and give greater weight to the purportedly "insidious" and "pernicious" effects of parental alienation (O v. O, 2008-2009).

The Decision Tree Invites Critiques of Protective Parents that Blame the Victim for the Consequences of Abuse and Undermine Child Safety

One of the ongoing tensions between the custody evaluation field and the domestic violence field is the tendency of some evaluators and researchers both to minimize the impact and severity of violent abuse and to hold mothers responsible for problems in a family with a violent abuser (Bancroft \& Silverman, 2002). It is not uncommon to see an evaluation or article that, like Drozd/Olesen's (2004) decision tree, discusses violence in the family while critiquing the victim-mother's response or parenting within that context (Fidler \& Bala, 2010; $H v . M, 2008 ; J v . J$, 2009; $O v$. $O, 2008-2009)$. Unfortunately, while the decision tree authors endeavor to be objective and fair, their analysis reflects some of the same tendencies to critique victims' responses in ways that have the effect of reducing the abuser's responsibility for the impact of his abuse while strengthening negative judgments of a victim-mother's parenting in the context of that abuse. In particular, the article's discussions of "counterproductive protective parenting" and "mediating variables" in the context of abuse both contribute to this problem.

THE ROLE OF THE NON-ABUSIVE PARENT

The article discusses the effects of abuse on a child by focusing on "child variables" and "parent variables" that "mediate" those effects (Drozd \& Olesen, 2004, p. 85). In brief, the mediating variables include each parent's "parenting style" and the child's "own biological and psychological hardiness..." (Drozd \& Olesen, p. 86). Relevant parenting styles include, for the "non-aggressor" parent, authoritative, authoritarian/aggressive, permissive/passive, neglectful, discouraged, and counter-productive protectiveness (Drozd \& Olesen, p. 91, Figure 14). Aggressor parents' styles may include authoritarian/aggressive, permissive/passive and neglectful, or sabotaging. Child variables include age, cognitive capacity, temperament, personality, prior trauma and losses, coping strategies, and resilience and 
vulnerability (Drozd \& Olesen, p. 88, Figure 12). To their credit, Drozd and Olesen discuss a number of important ways that aggressor parents may be poor parents, such as modeling destructive values including victim-blaming, sabotaging the mother's relationship with her children, and often utilizing similar aggression or control in their relationships with their children as they used in their adult relationship (Drozd \& Olesen, pp. 88-90). They also emphasize the importance of holding batterers accountable for their abusive behaviors, reciting Bancroft $\&$ Silverman's 12 "steps to change" for batterers (Drozd \& Olesen, p. 90, Table 4).

Also to their credit, the authors acknowledge that "some victim parents are very effective parents" (Drozd \& Olesen, 2004, p. 91) and that "the non-abusive parent's psychological state is very important simply because... research shows that the best way to help a child who has been exposed to domestic violence is to support the healing of the non-violent or victim parent" (Drozd \& Olesen, 92 [citation omitted]).

\section{COUNTERPRODUCTIVE PROTECTIVE PARENTING}

However, the majority of the discussion of non-aggressor parents is devoted to their weaknesses and failures. The main new contribution this discussion offers is the concept of "counter-productive protective parenting" (Drozd \& Olesen, 2004, p. 92). The authors' definition of this parenting style is striking: a parent who "is so scared and frantic that she is not effective in her efforts to protect her child" (Drozd \& Olesen, p. 95).

[A mother] may fail in protecting her children when the court grants the father unmonitored contact... In her mind, the system has failed her and she has failed her children... Her behavior may become counterproductive. The angrier she gets, the more frightened...the less likely that the custody evaluator or the court will see her as parenting in a manner that is in the best interest of her children. The more she acts this way, the less likely she is able to protect her children... Her behaviors are counter-productive and ber parenting style can be described by the same name [emphasis added] (Drozd \& Olesen, p. 97).

Those who have litigated cases on behalf of abused mothers seeking to protect their children are all too familiar with the failure of the system to credit mothers' attempts to protect their children. It is true that in some instances such mothers may become overtly angry, or perhaps extremely upset, and behave in ways that do not help their case. Nonetheless, the use of the label "counter-productive" to explain the system's failure to protect the child implies that it is her behavior which causes the system's failures. At the same time, the authors seem to acknowledge that her "counter-productive" response is in reaction to the system's own failures. 
"The system fails the protective, once abused, parent" (Drozd \& Olesen, 2004, p. 97). Yet by labeling such a reaction "counter-productive protective parenting" and suggesting that it is relevant to a custody evaluation, they unavoidably contribute to a misattribution of blame for the legal system's own failure.

Perhaps most troubling, the authors equate some mothers' reactivity or emotionality in response to the court's failures with their own inadequate parenting. "[H]er parenting style can be described by the same name." I can see no reason-and the authors offer none-why a person's reaction to a court's refusal to allow her to keep her child safe should be treated as a measure of her parenting skill or style. The one has nothing to do with the other. Yet, it is precisely this type of blurring that causes courts and evaluators to think that they are assessing a parent's parenting when what they are really assessing is-from a subjective viewpoint-the parent's interactions with the system and the evaluators themselves. Indeed, this blurring is consistent with the already problematic tendency of judges and evaluators to assess a parent's parenting capacity based on how he or she appears in court, how the parent interacts with them, or whether they like the parent. For instance, Jaffe, Lemon et al. (2003) have similarly pointed out that abuse survivors' anger, distrust, or suspicion toward court professionals "undermines their effectiveness in dealing with the court system and may result in adverse inferences drawn about their attitudes, parenting skills, and ability to promote a relationship with the other parent" (p. 62). These authors however, do not for a moment suggest that these "adverse inferences" are in any way legitimate or appropriate. On the contrary, while to some extent it may be unavoidable for human beings to judge others as parents based on their own interactions, one would hope that a thoughtful and deliberative discussion of the custody evaluation process such as that embodied by this article would avoid this pitfall. Indeed, one might even hope to see these leading evaluation authors acknowledge that a mother's parenting style or skills are in fact unlikely to be capable of assessment based on her interactions with system personnel or her responses to court-inflicted harm to herself or her children.

While Drozd and Olesen are careful not to over-generalize, I believe it is important to emphasize that to a remarkable degree many mothers remain appropriate and functional in the face of a court system that has in many cases turned on them and consigned their children to ongoing sexual and physical abuse ( $H$ v. M, 2009; O v. O, 2008-2009; Sullivan, Nguyen, Allen, Bybee, \& Juras, 2000; Wv. F, 2007). Such mothers' transcendent heroism in the face of the unique agony of watching their children and their own lives be destroyed by physical and sexual abuse permitted by the legal system in the name of "justice," has been heretofore unacknowledged and deserves serious examination by the social science field. 


\section{ADDITIONAL MEDIATING VARIABLES}

There is one more troubling aspect to the decision tree's discussion of "mediating variables." In assessing what victimized mothers contribute to the family dynamic and to the impact of a father's abuse on the children, the discussion unavoidably has the effect of distributing responsibility for an abuser's abuse on children between both parents. While on one level, it is true that victimized mothers' behaviors inevitably play a role in how children are affected by a father's abuse, on another level, it is-or should be-irrelevant to a court assigning custody. Upon identification of the abuse and its perpetrator, the difficulties that flow from abuse, including those exhibited by the victim, should be laid at the door of the perpetrator. Violent abuse is not on a par with a mother's "counter-productive" reaction to it. Yet, to give the mother's response the significance this discussion does is to subtly reduce the abuser's responsibility for his own abuse and to elevate the adult victim's shared responsibility for that same abuse.

The flawed logical extension of this kind of analysis can be seen in a recent case handled on appeal by this author. Here, the court found that the child was alienated from the abusive father due in part to his "temper" problems and in part to the abused mother's fear, which the court characterized as "understandable" and "legitimate," but which she failed to hide from the child. The mother's "understandable" fear, which according to the court affected the child, became the basis for assigning the father joint custody and increased access time, to attempt to counteract the child's alienation. In fact, this purported alienation-concededly caused at least in part by the father's adult abuse-became the basis for rebutting the presumption against joint custody to batterers. In essence, this type of reasoning rewards the abuser for the consequences of his abuse: Even if the mother's fear is due to bis violent conduct, so long as the child's alienation is even partly a reaction to the mother's feelings, it entitles him to more access. ${ }^{16}$

This kind of displacing of the natural consequences of abuse is an inevitable outcome of the multi-factoral approach. The emphasis on evaluating "everything," that is, both parents' parenting styles, behaviors, dysfunctions, and so forth, evenhandedly, even where one parent is abusive and the other is not, appears to be virtually a cardinal rule within serious custody evaluation practice and literature (Fidler \& Bala, 2010; Gould, 2006; Johnston, Walters, \& Olesen, 2005). Yet, while the scientific impulse for comprehensive and "multivariate" assessment is understandable, in the context of abuse, the treatment of abuse as simply one of many other factors, especially alienation, is inappropriate: It inevitably downgrades the significance and priority of abuse and abusers in favor of a more "equal" focus on both perpetrators and victims. After all, both are parents and both impact the children, and both have other strengths and weaknesses. Yet, if we recognize the true dimensions of the intentional harm of abuse, we would not treat these things 
as equivalent, because one is the unjust cause of harm, while the victim's primary deficits-particularly any negativity toward the abuser-are essentially a strategy of coping with that intentionally inflicted harm. In other words, both a scared or angry mother and an alienated child are caused by the abuse. Compensating the abuser for that fear and alienation simply rewards abuse.

Some may see this analysis as more concerned with fairness to the adults than the best interests of the child. However, more often than not, those two values coincide: As has been amply demonstrated empirically, and the "Safety First" article recognizes, men who batter their wives are more likely to abuse their children, and that risk increases after separation (Bancroft \& Silverman, 2002; Dalton et al., 2003; Drozd et al., 2004). Batterers are also apt to treat their children as owned objects subject to "power parenting," to be neglectful and indifferent to the children's needs, and to actively destroy their relationship with and trust in their protective mother (Bancroft \& Silverman, 2002; Radford \& Hester, 2006). But research indicates that many women who have been victimized manage to parent as well as other women (Sullivan et al., 2000), and those whose parenting has been impaired are likely to rebound once they separated and safe from the abuse (Drozd \& Olesen, 2004; Radford \& Hester). Moreover, for an abuser to be rewarded with custody teaches children a terrible lesson: at best, that violence and abuse is not a problem, and at worst, that violence and abuse is rewarded and to be emulated. For a mother who is victimized by an abuser to be denied custody (or primary custody) because her victimization purportedly renders her a less "friendly" parent to the father, teaches children a similar lesson: that abuse should have no impact on a parent's rights to their children and that victims must subordinate their own safety and suffering to the abuser. Thus, holding batterers accountable in the custody decision furthers not only fairness to the parents but also children's psychic and physical well-being.

Perhaps it is the decision tree's implicit commitment to evaluating the extent to which each parent contributes to potential harm for the children that fuels the tilt of the discussion toward non-aggressor parents' parenting flaws rather than toward recognition of their often heroic accomplishments in the face of extreme stress and abuse. A balanced discussion of non-aggressor parents in such families would also have to describe the remarkable efforts and sanity that many mothers bring to insulating and protecting their children from the abuse, maintaining nurturance and love, and keeping their lives functioning, while under an onslaught of aggression, violence, and threats from the father (Radford \& Hester, 2006; Sullivan et al., 2000). Had this article included such a discussion, it would provide an important counter-balance to many evaluators' tendency to blame mothers for whatever difficulties children have, even in families with 
an abusive father. In addition, it would have helped evaluators to notice the extraordinary state of siege under which some mothers live and the remarkable efforts many make to insulate their children from the chaos around them.

Of course, the net effect of all of these things is that non-offending mothers who are struggling with the impact of abuse and judicial denial are likely to be seen as equally problematic as (or more problematic than) their abusers. But, so long as non-abusive mothers are seen as equally problematic as - even if in different ways than-abusive fathers, this evenhanded distribution of responsibility for the children's problems inevitably leads to a dilution of concern about the abuser's abuse. The unavoidable result is evaluators' and courts' failures both to adequately recognize and value danger and risk of future abuse and to adequately ensure the children's (and mother's) safety.

\section{THE DECISION TREE'S LACK OF GUIDANCE ON WEIGHT OR PRIORITY TO DIFFERENT FACTORS INVITES A CONTINUED FOCUS ON ALIENATION ATTHE EXPENSE OF ABUSE CONCERNS}

Drozd and Olesen's emphasis on "multivariate" and comprehensive evaluations of abuse, alienation, and developmental/behavioral theories, while offering the appearance of fairness and objectivity, also fails to cabin evaluators' discretion and judgment in any respect. Thus, an evaluator who believes that women often lie about abuse and brainwash children can easily apply the decision tree to conclude that the alienation is significant and the abuse is not, even if there is evidence of severe violence and abuse by one parent against the other. ${ }^{17}$ Even an evaluator who does their best to be open-minded receives no guidance on how to weigh the multiple problems in the family. What if there is abuse, paternal sabotaging of the mother, and poor parenting by the mother? How does a truly neutral evaluator sort through all these findings and reach a bottom line recommendation? As discussed earlier, experts on abuse and custody generally point in the same direction: In most cases abuse should trump the other factors because abuse poses the greatest risk to children, children's safety and feelings of safety are essential to their well-being, and because where there is abuse, it is likely to be the source of most of the other problems in the family (Dalton et al., 2003; Meier, 2003; Stark, 2009). For this reason numerous state statutes, Congress, and the National Council of Juvenile \& Family Court Justices elevate domestic violence above the many other factors commonly considered in custody decisions (American Bar Association Commission on Domestic Violence, 2008; Dalton et al., 2006; H. Res. 172, 101st Cong., 2nd Sess, 1990; National Council of Juvenile \& Family Court Judge, 1994). In contrast, the decision tree sacrifices clarity and priority to abuse on the altar of "multivariate" evaluation 
and permits even affirmative abuse findings to be trumped by purported alienation.

\section{ALIENATION: A TEMPEST IN A TEAPOT}

The foregoing discussion implies that the fundamental critique of alienation as a defining principle in custody litigation has more to do with context than with the intrinsic validity of the concept. Indeed, both the evaluator community (and Drozd and Olesen, 2004) and domestic violence communities are in agreement that alienation behaviors are commonly, if not most commonly, committed by abusive fathers (Bancroft \& Silverman, 2002; Drozd \& Olesen; Johnston \& Kelly, 2004; Johnston et al., 2005). In addition, where a mother malevolently turns the children against a loving father, or vice versa, I would agree that alienation is a legitimate concern, although the question remains whether and how a court can remedy or prevent it. The current problem with alienation's use in family courts is that it is so commonly used to falsely deny abuse and that it is selectively invoked against mothers far more often than against alienating fathers. To their credit, Drozd and Olesen, and even Gardner (2006) assure readers that the use of alienation to deny real abuse is improper and not how it was intended. But, these denials are unpersuasive in light of both (1) the historical development of PAS expressly for use against abuse allegations; (2) the common definition of alienation as involving false abuse allegations (Fidler \& Bala, 2010) (citations omitted); (3) the rampant misuse of PAS and alienation to deny true abuse; and (4) the empirical evidence that true alienation is, at best, a minor problem in the vast majority of separating families.

The first three of these are discussed in the previous sections and in this author's prior work. ${ }^{18}$ Regarding the fourth-the actual prevalence of alienation-leading alienation researcher Janet Johnston's (2005) own research has demonstrated that even where the majority of divorcing parents used alienating behaviors, only $20 \%$ of the children were actually alienated from (i.e., rejecting and angry or negative toward) the other parent. Additionally, most of these had legitimate reasons for the estrangement, including neglectful, abusive, or other non-nurturing behaviors by the disliked parent. It is important to bear in mind that the largest study of custody litigation to date found that only $9 \%$ of divorcing parents litigated their cases in court, and only $4 \%$ actually took their cases all the way to trial (Emery et al., 2005; Maccoby \& Mnookin, 1992). Of the $9 \%$ who litigate, we can assume based on Johnston's study that a majority engage in "alienating" behaviors, but only approximately $20 \%$ of children are even negatively affected. Moreover, a portion of these are estranged for good reason, according to Johnston as well as Drozd and Olesen (2004). What does this mean for alienation theory? It would seem that as an objective matter, alienation is, simply, a very minor 
problem for the courts. Only in a very small proportion of cases-something less than $2 \%$ (i.e., $20 \%$ of $9 \%$ ) of the total population of divorcing familiesrequire courts involvement concerning alienation. Even of these, a significant proportion of children are hostile due to the disfavored parent's own conduct or other developmental reasons, meaning their so-called "alienation" cannot possibly be brought to bear in favor of the disfavored parent, thus making it simply irrelevant to the adjudication of access rights between the parents.

The relative insignificance of alienation as an empirical problem is underlined by the fact that there has yet to be adduced any empirical research documenting long-term harm to children from pathological (as opposed to justifiable) alienation. Rather, assumptions about the harm of alienation are derived from clinicians' personal clinical experiences (Johnston \& Kelly, 2004). But these assessments may well be circular. That is, those who believe alienation and loss of closeness to (typically) a noncustodial father is one of the worst harms that can befall a child are inclined to attribute children's problems to that alienation rather than to any emotional or physical abuse in the family. While Johnston and Kelly suggest that "preliminary data" do support clinical observations, indicating that children who are alienated from one parent suffer more behavioral problems than their non-alienated counterparts, this analysis does not appear to account for the likely contribution of child abuse or other destructive parenting to the children's problems-factors that they elsewhere acknowledge contribute to children's alienation (Johnston \& Kelly, 2004). Indeed, research (and litigation experience) amply demonstrates that evaluators and courts routinely, often mistakenly, attribute children's behavioral difficulties to poor custodial (largely maternal) parenting rather than to a noncustodial father's history of abuse ( $O v$. O, 2008-2009; Radford \& Hester, 2006; Stark, 2009).

In contrast, while all who work with clients in the field, this author included, are apt to draw inferences and develop beliefs based on their own practice and predilections, it bears noting that, in contrast to alienation, the prevalence of violence and abuse in custody litigating families, as well as the harm caused by abuse, is amply empirically documented. Research from multiple sources, including studies in different courts of cases referred for evaluation or mediation, indicates with remarkable consistency that approximately $75 \%$ of contested custody cases involve a history of domestic violence (Jaffe, Crooks, \& Poisson, 2003; Johnston, 1994; Johnston \& Campbell, 1993). While some rare custody-related research identifies the mother as the perpetrator in a subset of cases (Johnston \& Campbell; Kelly \& Johnson, 2008 ), the fact that violence and abuse is a widespread problem among custody litigants is really not debatable. In addition, unlike alienation, there is little debate that violent or sexual abuse in the family is destructive to children both when they merely witness abuse between their parents and when they are directly abused (Bancroft \& Silverman, 2002; Drozd et al., 2004). While many in the system may over time become accustomed and somewhat 
desensitized to allegations of violence, domination-based battering, which is inflicted to instill fear, is a kind of terrorizing which is profoundly traumatizing to its direct victims and children who witness it. "Psychological trauma is an affliction of the powerless.... "Chronic childhood abuse takes place in a familial climate of pervasive terror, in which ordinary caretaking relationships have been profoundly disrupted... The omnipresent fear of death is recalled in the testimony of numerous survivors [of childhood abuse]" (Herman, 1992, pp. 33, 98). This is true for children who "merely witness" their parent's victimization, as well as those who are directly abused. Courts and evaluators would do well to remember this.

In short, the lack of empirical evidence of the harm of alienation; the affirmative evidence that even intentional alienation rarely occurs and that when it does it is often due to the disfavored parent's own conduct; and the undeniable history of the misuse of alienation claims to discount and deny abuse allegations, all point to the conclusion that the pervasive focus on alienation in family courts is little more than another means of putting shared parenting - or fathers' rights-above all else (Jaffe, Lemon et al., 2003). Indeed, in the name of remedying mothers' supposed alienation of children, more and more children are being completely cut off from their mothers (Petition in Accordance with Inter-American Commission on Human Rights, 2007; Lesher \& Neustein, 2005; $M v$. M, 2010). In these cases, the consequence for alienation not only replicates the very harm it claims to correct-it exceeds the consequence normally exacted for abuse. Abusers typically receive at least supervised visitation, and in many cases, unsupervised access or joint custody. It is, therefore, difficult to avoid the conclusion that the use of the alienation theory is really about elevating fathers' rights over mothers' rights and children's best interests. To their credit, Johnston and Kelly (2004) have begun to directly challenge the shared parenting "religion" and to call for individualized assessments of each child and their relationships with their parents to replace the blanket assumption about the controlling importance of maintaining active contact with the non-custodial parent. I have no doubt that Drozd and Olesen (2004) share that perspective and goal.

\section{ALTERNATIVE APPROACH: PUTTING THE TEMPEST BACK INTO THE TEAPOT}

If the court system's focus on alleged alienation is distorted and misplaced, and if the decision tree's multivariate approach also fails to do justice to the realities of abuse and alienation, what is a preferable approach? I offer the following steps to outline an approach that reflects the realities of abuse and alienation while cabining the potential for misuse of the alienation concept to falsely deny abuse, but not rejecting entirely the possibility that 
alienation by a parent is the dominant and destructive cause of a child's estrangement from the other parent.

1. Assess abuse first. Abuse should always be assessed-first-whenever there are allegations of abuse. The outcome of this assessment could short-circuit the remaining evaluation: If abuse claims are verified, or substantial risk exists, the remainder of the evaluation should be guided by safety and healing as the dominant concerns, with relationship preservation as the second concern.

2. Expertise in abuse is required. Evaluators who lack meaningful expertise should be required (as is implied by the APA's child custody evaluation guidelines, [APA, 1994, 2009]) to bring an outside expert into the evaluation. Real "expertise" requires more than one or two continuing education seminars. It requires in-depth training and experience in working with abused children or adults. Evaluators who possess a predisposition to believe that children who allege abuse have been brainwashed or coached are evaluators who lack appropriate expertise and who are operating from ignorance or bias. There is little objective empirical support for this widespread belief (Lyons, 1998-1999), and it skews an evaluation in a direction that is unacceptably risky for children. It is precisely because assessments of abuse (like alienation) are notoriously dependent on the assessor's predispositions to believe or not believe such claims, that actual training (either a specialized degree or post-degree) and some specialized work on abuse is a necessary pre-requisite for a valid assessment. Additional indicia of abuse expertise might include research or publications in the field, subscriptions to abuse-related journals, participation in specialized conferences, and so forth.

3. Once abuse is found, alienation claims by the accused abuser are not considered. Virtually every article about alienation and abuse, including Drozd and Olesen's (2004), gives lip service to this principle: that if abuse is real, then alienation is not (p. 81). Yet Drozd and Olesen's decision tree is explicitly built around the principle that both such possible causes of estrangement must be explored. As described in a previous section, this "multivariate" approach tilts the assessment dangerously away from recognizing the real implications of abuse.

There is one exception: Derogatory treatment of a child's mother is common by batterers and is simply one of an array of psychological strategies that abusers use to harm mothers and children. This widely recognized aspect of battering, which Drozd and Olesen call "sabotaging" (2004, p. 94) and has been termed variously "tangential spouse abuse" and "domestic violence by proxy" by other leading experts (Stark, 2009; Leadership Council, 2009), is simply part of the pattern of abuse and should be part of the abuse assessment. How much weight a court or evaluator will want to give to this type of alienating (or estranging or 
sabotaging) conduct is an open question. In this author's view, in the ordinary abuse case, the abuser's abuse is of greater concern than their alienating or sabotaging conduct, with one exception: When abusers are given custody or general control over the child, they too often intentionally destroy the child's relationship with his or her protective and caring mother (Petition in Accordance with Inter-American Commission on Human Rights, 2007). The harm caused these children (not to mention their mothers) by the combination of abuse and intimidation and intentional "alienation" can only be extreme-not so much because of the loss of one parent, but because of the child's loss of ability to trust in their protective parent, the essential relationship for their healing and recovery from abuse (Bancroft \& Silverman, 2002). Of course, if these guidelines are implemented, it is to be hoped that abusers will not be given custody at the expense of the abuse-alleging mother, thereby obviating the potential for this type of truly devastating "alienation" by an abuser See \#4.

4. Where abuse allegations are not confirmed, the allegations themselves may not be treated as evidence of alienation. This may well be the most controversial portion of this article-and the most important. Perhaps, it is best explained with a small thought experiment: When fathers allege that mothers or their new partners are abusing the child and/or bring the child to a counselor for such abuse, but the court does not confirm the allegation, would it be usual to treat the father as a pernicious alienator from whom the child must be removed and protected? I have never heard of this happening, nor do I believe most experienced family lawyers or evaluators would expect, or even advocate for, such treatment. The same standard should hold true for mothers alleging abuse.

What this means is that alienation sbould not be linked to abuse allegations at all. If alienation is a serious concern, then it is one independent of abuse allegations. To treat abuse allegations as the hallmark of alienation, as Gardner invited and the alienation community continues to do, is simply to fall into the trap illuminated previously: of misusing a claim of alienation to defeat, neutralize, or undermine the seriousness or validity of allegations of abuse. The two concerns should stand or fall on their own.

5. Allenation claims are independently evaluated only under limited conditions: Only if (1) all possible "natural" reasons for the child's extreme hostility to the other parent (such as affinity, development, or the disfavored parent's own conduct) have been ruled out; and, (2) there is identifiable intentional alienating behavior by the "aligned" parent. As Johnston (Johnston, Walters, \& Olesen, 2005) and others (Fidler \& Bala, 2010) are increasingly noting, children may be estranged or alienated from one parent over time, even in intact families, for myriad reasons, including developmental changes, personality differences, children's and parents' 
own vulnerabilities or needs, and so forth. Family courts, while seeking to assess the "best interest of the child" cannot possibly hope to fully and accurately assess all of these factors, let alone control for or correct them. Even if they could, family courts' legitimate role is limited to awarding custody to one parent or both, not to curing all interpersonal ills in the family. Therefore, to ensure that alienation claims are not merely rebutting or minimizing abuse, courts' and evaluators' alienation assessment should be limited to identifying those presumably very few cases in which one parent actively and gratuitously undermines the other parent's relationship with the children to a degree that is detrimental to the child.

Once a child is determined to be unreasonably hostile to the other parent (i.e., where the child refuses to spend time or is incorrigibly resistant with one parent) and there is no "natural" developmental or justifiable reason, the evaluation must seek to determine if this hostility has been fueled by the other parent. (Alienation concerns should not be limited to that committed by a custodial parent against a noncustodial parent. Many noncustodial parents use such conduct to undermine children's relationships with their custodial parents.) In assessing for parentallycaused estrangement or alienation, protective measures such as filing court protective petitions or going to Child Protection must not be considered. Otherwise, the alienation assessment becomes once again a function of disbelieved abuse allegations.

Empirically, true alienation will be at issue in only a tiny fraction of cases. As noted previously, Johnston (2005) found that, even with alienating conduct by parents, only $20 \%$ of children in contested custody litigation were actually "consistently negative" toward-only about 6\% were "extremely rejecting" of-one parent, and many of these had good reasons. Once those families with abuse histories or other valid reasons for the estrangement are excluded, the number of litigating families where one parent is causing a child's alienation from the other parent must be extremely small.

Note that this approach excludes cases where the parent is engaged in alienating conduct but the child is not in fact alienated. It also excludes cases where the child is incomprehensibly hostile but the preferred parent is not the cause.

6. Only conscious intent and specific behaviors may constitute alienating conduct. Gardner popularized the notion that mothers may unconsciously, without malevolence, seek to alienate children from their father (Gardner, 1991, 1987). As some case examples herein and elsewhere (Petition in Accordance with Inter-American Commission on Human Rights, 2007), have demonstrated, evaluators' and courts' tendency to psychoanalyze mothers and to attribute alienating behavior to their unconscious, has made it possible to accuse a mother of alienation - and thereby dismiss abuse claims-even when she has done notbing to alienate the child. 
Thus, in one of the cases described in the previous sections, the court explicitly found that the mother was not coaching the child but suggested that the child might be inventing sexual abuse because she "senses her mother's dislike for her father," among other things ( $W v . F, 2007$ ). Of course, this theory is sufficient to negate all child abuse allegations in all cases since inter-parental hostility can be inferred in most such litigation. Such unfounded and frankly nonsensical judicial speculation has been legitimized by the widespread acceptance of the pop psychology attached to the PAS theory. The best cure is a clean one: Psychoanalyzing should be prohibited; only identifiable behaviors should be considered in assessing for alienation. This recommendation is consistent with Drozd \& Olesen's warning against evaluators "attempt[ing] to guess at someone's motivation or...[posit] some unconscious underlying family dynamic" and urging that evaluators limit themselves to behavioral observations instead in order to minimize error (Drozd \& Olesen, 2004, 80).

7. Remedies for confirmed alienation are limited to healing the child's relationship with the alienated parent. Under this proposal, if legally cognizable alienation is found, evaluators should not seek to undermine the child's relationship with the preferred parent, but rather to strengthen the child's relationship with the parent from whom $s /$ he is alienated. Therefore, family therapy between the child and the alienated parent, therapy for the child, and/or therapy for the preferred parent, might be appropriate. Orders to both parents to cease any derogatory discussion of the other parent may be appropriate, but forced change of custody is not, at least not until the child's relationship with the alienated parent is sufficiently healed to make the child comfortable with such a prospect. While at the current time this may be a painful and difficult pill for mothers whose children have been successfully alienated from them by an abusive father who possesses custody, such outcomes should become rarer once alienation is no longer wielded as a sword against mothers who raise abuse concerns. Moreover, this proposal does not ignore such conduct; it merely requires it to be addressed as part of an abusive pattern and not as "alienation" per se.

Those who see such remedies as unacceptably weak would do well to recall that extreme alienating conduct by an abuser, such as requiring the children to watch him beat their mother, calling her a whore, and teaching them to disrespect and ignore her, has historically not been cause for much judicial concern. If such conduct did not rise to the cognizable level when committed by violent abusive fathers, it is hard to see why less egregious conduct by nonviolent mothers should be of far greater concern. Moreover, Johnston's (Johnston, Walters, \& Olesen, 2005) research confirms what many in the field know: That children are resilient and that they are not easily brainwashed into rejecting another parent, at least not without active abuse, coercion, and terrorization. 
Courts and evaluators should operate from a healthy appreciation for the range of imperfect parenting that children everywhere survive and for the strength of children's hard-wired love for both parents. They should ensure that loving relationships are made available and invited to flourish, and should trust that children will discern the truth about their loving parents so long as they are able to experience them directly.

\section{CONCLUSION}

Drozd and Olesen's (2004) decision tree, along with their earlier article "Safety First," are important attempts to bring objectivity and sensitivity to evaluators' assessments of abuse and alienation. Unfortunately, while the desire to be neutral, objective, and open to all hypotheses is understandable and honorable, the realities of abuse, its routine denial by evaluators and courts as well as abusers, the rampant misuse of the alienation concept, and its historical pedigree as a strategy for denying abuse, make the multivariate approach more of a tool for denial than for truth. Real objectivity and genuine truth about abuse and alienation requires a more grounded understanding of both the implications of abuse and the limited validity of the alienation concept, if evaluators and courts are to fairly and accurately determine parental access in a manner that truly protects children's best interests.

\section{NOTES}

1. The concept of a "Parental Alienation Syndrome," a phenomenon where a custodial parent (usually the mother) would actively seek to subvert the children's relationship with their noncustodial parent (usually the father) by alleging child sexual abuse and other means, was first coined by Richard Gardner, M.D., and was widely adopted, explored, and advocated within the worlds of courts and forensic: evaluators (Bruch, 2001; Hoult, 2006; Meier, 2009). Over time the scientific validity of a parental alienation "syndrome" has been largely rejected by leading professionals in the mental health and legal fields (American Psychological Association [APA], 1996; Dalton, Drozd, \& Wong, 2004, rev. 2006; Ragland \& Fields, 2003). However, "parental alienation," not as a scientific "syndrome," but simply as a factual behavioral phenomenon, continues to be treated by leading mental health researchers and evaluators as a central defining issue in custody evaluations and adjudications (Drozd \& Olesen, 2004; Kelly \& Johnston, 2001). The extent to which "PA" differs from or is similar to PAS is debatable; see Meier, 2009a.

2. While the theory of alienation is not inherently gendered, it is used far more often against mothers than fathers, in part because it evolved from PAS, which was invented specifically with mothers in mind. See e.g., Gardner, 1992, p. 129; Gardner, 1987, pp. 127-28, 131, 188 (describing mothers who falsely allege child sexual abuse). Regardless of the intent of particular proponents, both theories are most easily applied against mothers because both challenge the credibility of allegations of abuse, which are most commonly made by women against men.

3. See, e.g., http://www.mediaradar.org/. The label "father's rights" is ambiguous; without knowing more about such groups it would not necessarily signify opposition to advocacy against domestic violence. However, many fathers' (or "men's") rights groups are opposed to domestic violence advocacy, deny the prevalence of domestic violence and its relationship to male domination of women, and seek to weaken legal protections from abuse, all in the name of an absolute right to "shared parenting" and strong assertions that many women fabricate abuse (1)awson, 2009; Sack, 2004). 
4. Although the decision tree also references the child's "age and stage-appropriateness" of the child's "behavior," the article does not explain what is meant by the term, but it appears that for purposes of this article, concerns about a child's behavior are limited to those connected to their relationships with parents. Even the discussion under the heading concerning "Development" focuses solely on child-parent relationships. See, e.g., id. at 73 et seq ("Many, if not most, children in non-abusive families have equal... emotional relationships with their parents... some children ... do not").

5. Even Richard Gardner acknowledged that PAS is sometimes misused in this way (Gardner, 2002, p. 100).

6. The article does somewhat vaguely suggest that even if the child's behaviors are appropriate and their relationships with parents are all right, an evaluator may still want to apply the decision tree, including evaluating safety. But this is an understated possibility, rather than a strong recommendation, and it is not reflected in the tree (Drozd \& Olesen, 2004, p. 71). Moreover, as noted in the following sections, the safety analysis is limited to instances of prior findings of abuse or new court orders to do such an assessment. It is unlikely that a court would order this without a request or recommendation from the evaluator; courts typically defer to evaluators' own professional judgments regarding whether and how to conduct an evaluation. It is unclear why the tree does not urge evaluators to proceed with an abuse/risk assessment in all cases where abuse is alleged.

7. While the general thrust of the "Safety First" article is laudable and the piece offers valuable background information to evaluators about abuse and its impact on children, even this article is also somewhat ambiguous about how evaluators can and should assess future safety of children: "The first step directs the evaluator to address the child's immediate safety. The second and third steps emphasize the evaluation of the child, including the child's psychological functioning and intimate relationships" (Drozd, Kuehnle, \& Walker, 2004, p. 95) While emphasizing the need to assess for abuse and safety, rather than explaining how one assesses safety (most domestic violence experts will say that the only way to predict future risk is to assess past abuse) and how to structure visitation/custody recommendations around safety, it instead moves into a relationship assessment, regardless of whether danger is found. More confusingly, the use of the phrase "immediate safety" seems to limit the safety focus to only "immediate" concerns such as visitations right now during the litigation (when most abusers can be expected to be on best behavior), rather than on the long-term post-litigation safety needs which a custody court must determine. It appears, although neither article is explicit, that the article under review here is actually the completion of the "Safety First" Model (Drozd, Kuehnle, \& Walker, 2004, p. 89). ("The final steps in this model include the development of multiple hypotheses, specialized assessments of the child and parents, and the crafting of recommendations for the court that are specific and unique to the case at hand; these will be discussed in a future article by the authors").

8. This author's focus is on male batterers of women for several reasons. First, while some research suggests that women use violence more often than has been recognized (Johnson, 2008), women's use of violence is rarely connected to a control and domination agenda, and is far less injurious or oppressive to its male victims (Johnson, 2008; Stark, 2007, 2009). The differences in harm to children from exposure to mere "hitting" between adults as opposed to the gender-based use of fear to impose power and control over the victim are not well established and await serious research. However, as is true of most specialists in domestic violence, when this author speaks of adult abuse or domestic violence the reference is to battering which involves the ongoing gender-based exercise of power and control (Farney \& Valente, 2003; Dalton, Carbon, \& Olesen, 2003). Therefore, the terms "abuse" and "battering" refer not only to acts of violence but to "coercive control," defined as "tactics to intimidate, humiliate, degrade, exploit, isolate, and control," which are often accompanied by "low-level violence such as pushes, slaps, hair-pulling, kicks, and grabbing" (Stark, 2009, p. 294). The research literature is increasingly identifying coercive control as equally and sometimes even more destructive to its direct victims and potentially to children, than "mere" violence (Stark, 2009, pp. 294-95).

9. Reporting an evaluator's independent concerns about abuse to child protection, as suggested by the authors, in lieu of doing the evaluation oneself (Drozd \& Olesen, 2004) would be a futile gesture. Child protection agencies are notoriously reluctant to fully investigate when allegations of child abuse are lodged by a custody litigant. (See, e.g., Illinois DCFS policy manual, http://dcfswebresource.dcfs.illinois. gov/downloads/procedures/procedures_300.pdf ("information about abuse allegedly committed by a father obtained from a young child who has been in the custody of a mother involved in a bitter divorce with the father may be less credible" Lesher \& Neustein, 2005). Moreover, if the allegation is "merely" that the child may have witnessed adult abuse in the home, in most states that would be per se insufficient predicate for a child abuse investigation (Weithom, 2001). Nonetheless, as the literature and domestic 
violence experts universally agree, where there has been adult abuse there are potential risks to the chiidren from the abuser, regardless of whether past child abuse can be demonstrated. These are precisely the forward-looking risks a custody evaluator should be assessing, which is in contrast to CPS agencies' limited focus on whether past abuse can be sufficiently proven to justify State intervention.

10. See, generally, Dawson, 2009. Not only fathers' rights extremists but a growing number of courts are viewing allegations of child or adult abuse by a protective parent as inalevolent or pathological, without serious investigation of their credibility. This trend has been recognized in the literature: "If [a mother] presses claims of abuse during a custody dispute, she is likely to be labeled uncooperative, selfish, or even vindictive" (Stark, 2009, p. 289).

11. This author has learned of several cases (one in my own caseload) in which the mother was found to have "alienated" the children from their father--and the father awarded increased custody-by virtue of her sadness about potentially losing her children and fear of the adult abuser, and her purported failure to hide her feelings from the children. Other organizations and experts report that this type of "blaming the victim" is not uncommon as a reason courts reduce or terminate custody of abused mothers even while recognizing that they are not malevolent or intentionally alienating the children.

12. Domestic violence organizations that do not necessarily specialize in custody nonetheless report that they are being flooded by calls for help from protective mothers in family court litigation who are losing custody to abusers or being forced to subject their children to abuse during visitation. 'This author's organization, DV LEAP, receives 2-5 desperate calls or emails of this sort per week.

13. See cases described in previous sections. In the trial this author completed in 2006 (referenced in example \# 4), the mother's second petition for a Civil Protection Order on behalf of her 4-year-old, which was filed after the urgings of the child's therapist and Children's Hospital personnel, triggered a counter Motion to Show Cause why the mother should not be held in Contempt for "interfering with visitation" by filing petitions for protection. The court never dismissed the contempt motion or ruled directly on it. While the court never ruled on the contempt motion it also did not dismiss it as invalid, and in the visitation litigation it did accept the father's denials of the sexual abuse, a position that was thoroughly rejected on appeal (Wilkins v. Fenguson, 928 A.2d 655 (D.C. App. 2007)).

14. It is often noted that mothers are uniquely subject to critique as parents to a far greater degree than fathers, due to our cultural history in which fathers were traditionally not expected to be involved with children. Crudely put, fathers nowadays are often considered heroes if they engage with their children, let alone assist in raising them. In contrast, mothers are considered flawed if they fail-as most doto live up to an idealized image of the always loving, always available, and always selfless mother. "Being a Good Father is a reasonable, attainable goal; you need only be present and supportive. Being a Good Mother, as defined by mothers themselves, is impossible... The Good Mother does not exist, and she has never existed" (Waldman, 2010, p. 11). "For the tedious and messy bits of my childhood my father was, like most fathers of his generation, absent... My mother did all the dirty work, and without receiving an ounce of emotional credit for it" (Lewis, 2009, p. 10).

15. This occurred in one of this author's ongoing cases, resulting in the child's being subjected to weekly sexual, physical, and emotional abuse as a result of the custody evaluator's denial of the past adult abuse and other violence and its implications, and the pathologizing of the angry, protective and traumatized mother (Record in $H v . M, 2008$ ).

16. As this article goes to press, the appeal in this case is pending (Record in J. v. J, 2009).

17. It does not seem as easy for an evaluator who believes that abuse claims are always true and alienation claims false, to propagate that bias through the decision tree, because the tree requires an evaluator to focus on alienation and parental relationships to a degree that will confound the single-factor focus on abuse that such an evaluator might instinctively prefer. In this sense, the tree is tilted toward an alienation-focused evaluation, as noted previously.

18. See Meier, 2009.

\section{REFERENCES}

Adams, M. A. (2006). Framing contests in child custody disputes: Parental Alienation Syndrome, child abuse, gender, and fathers' rights. Family Law Quarterly, $40(2), 315-338$. 
American Bar Association Commission on Domestic Violence (2008). Child custody and domestic violence by state, statutory survey. Retrieved October 19, 2010, from http://www.abanet/domviol/docs/custody.pdf.

American Psychological Association (APA). (1994). Guidelines for child custody evaluations in divorce proceedings. American Psychologist, 49(7), 677-680 [currently superseded by 2009 Guidelines].

American Psychological Association. (APA). (1996). Violence in the family: Report of the APA Presidential Task Force on Violence in the Family. Washington, DC.

American Psychological Association (APA). (2009). Guidelines for cbild custody evaluations in family law proceedings. Retrieved from http://www.apapracticecentral.org/ce/guidelines/child-custody.pdf.

Bancroft, L., \& Silverman, J. (2002). The Batterer as parent: Addressing the impact of domestic violence on family dynamics. Thousand Oaks, CA: Sage Publications.

Bruch, C. S. (2001). Parental Alienation Syndrome and parental alienation: Getting it wrong in child custody cases. Family Law Quarterly, 35, 527.

Bowermaster, J. (2002). Legal presumptions and the role of mental health professionals in child custody proceedings. Duquesne University Law Review, $40,265-311$.

Dalton, C., Carbon, S., \& Olesen, N. (2003). High conflict divorce, violence, and abuse: Implications for custody and visitation decisions. Juvenile \& Family Court Journal, 54(4), 11-33.

Dalton, C., Drozd, L., \& Wong, F. (2004, rev. 2006). Navigating custody and visitation evaluations in cases with domestic violence: A judge's guide, National Council of Juvenile EFamily Court Judges \& State Justice Institute.

Dawson, J. (2009). Introduction to the fathers rights movement. In E. Stark \& E. Buzawa (Eds.) Violence Against Women in Families and Relationships, 2, 165-190.

Drozd, L. M., Kuehnle, K., \& Walker, L. E. A. (2004). Safety First: A model for understanding domestic violence in child custody and access disputes. J. Child Custody, 1(2), 75-103.

Drozd, L. M., \& Olesen, N. W. (2004). Is it abuse, alienation, and/or estrangement? A Decision Tree. J. Child Custody, 1(3), 65-106.

Edleson, J. L. (1999). The overlap between child maltreatment and woman battering. Violence Against Women, 5(2), 134-154.

Emery, R. E., Otto, R. K., \& O'Donohue, W. T. (2005). A critical assessment of child custody evaluations: Limited science and a flawed system. Pych. Sci. in the Pub., 6(1), 1-29.

Faller, K. D. (1998). The Parental Alienation Syndrome: What is it and what data support it? Child Maltreatment, 3(2), 100-115.

Farney, A. C., \& Valente, R. L. (2003). Creating justice through balance: Integrating domestic violence law into family court practice. Juvenile E Family Court Joumal, 54, 35-55.

Fidler, B. J., \& Bala, N. (2010). Children resisting postseparation contact with a parent: Concepts, controversies, and conundrums. Family Court Review, $48(1), 10-47$.

Friedlander, S., \& Walters, M. G. (2010). When a child rejects a parent: Tailoring the intervention to fit the problem. Family Court Review, 48(1), 98-111. 
Gardner, R. A. (1987). The Parental Alienation Syndrome and the differentiation between fabricated and genuine child sex abuse. Cresskill, N.J.: Creative Therapeutics.

Gardner, R. A. (1991). Sex abuse bysteria: Salem witch trials revisited. Cresskill, N.J.: Creative Therapeutics.

Gardner, R. A. (1992). The Parental Alienation Symdrome: A guide for mental bealth and legal professionals. Cresskill, N.J.: Creative Therapeutics.

Gardner, R. A. (2006). Basic facts about the Parental Alienation Syndrome, definition of the Parental Alienation Syndrome. Retrieved from http://www.rgardner.com/ refts/pas_intro.html

Gelles, R. J., \& Conte, J. R. (1990). Domestic violence and sexual abuse of children: A review of research in the eighties. Journal of Marriage and Family, 52(4), 1045-1058.

Gould, J. W. (2006). Conducting scientifically crafted child custody evaluations (2nd ed.). Sarasota, FL: Professional Resource Press.

H v. M, (2008) (on file with author).

H. Res. 172, 101st Cong., 2nd Sess. (1990). Washington, DC: U.S. Government Printing Office.

Hart, B. (1992). State codes on domestic violence: Analysis, commentary and recommendations. Juvenile E Family Court Journal, 43(4), 3-81.

Herman, J. (1992). Trauma and recovery. New York, NY: BasicBooks.

Hoult, J. (2006). The Evidentiary admissibility of parental alienation syndrome: Science, law and policy. Children's Legal Rights Journal, 26(1), 1-61.

J v. J (2009). (on file with author).

Jaffe, P. G., \& Crooks, C. G. (2005). Understanding women's experiences parenting in the context of domestic violence: implications for community and court-related service providers, Retrieved from http://www.vaw.umn.edu/ documents/commissioned/parentingindv/parentingindv.html

Jaffe, P. G., Crooks, C. V., \& Bala, N. (2009). A framework for addressing allegations of domestic violence in child custody disputes. Journal of Cbild Custody, 6, 169-188.

Jaffe, P. G., Crooks, C. V., \& Poisson, S. E. (2003). Common misconceptions in addressing domestic violence in child custody disputes. Juvenile E Family Court Journal, 54, 57-67.

Jaffe, P. G., \& Geffner, R. (1998). Child custody disputes and domestic violence: Critical issues for mental health, social service, and legal professionals. In Holden, Geffner, and Jouriles (Eds.), Children Exposed to Marital Violence: Theory, Research, and Applied Issues 371-408.

Jaffe, P. G., Lemon, N. K. D., \& Poisson, S. E. (2003). Child custody and domestic violence: A call for safety and accountability. Thousand Oaks, CA: Sage Publications, Inc.

Johnson, M. P. (2008). A Typology of domestic violence: Intimate Terrorism, Violent Resistance, and Situational Couple Violence. Boston, MA: Northeastern U. Press.

Johnston, J. R. (1994). High-conflict divorce. The Future of Cbildren, 4(1), 165-182. 
Johnston, J. R. (2005). Children of divorce who reject a parent and refuse visitation: Recent research and social policy implications for the alienated child. Family Law Quarterly, 38, 757-775.

Johnston, J. R., \& Campbell, L. E. G. (1993). Parent-child relationships in domestic violence families disputing custody. Family and Conciliation Courts Review, 31(3), 282-298.

Johnston, J. R., \& Kelly, J. B. (2004). Commentary on Walker, Brantley, and Rigsbee's (2004) 'A critical analysis of Parental Alienation Syndrome and its admissibility in the family court.' Joumal of Child Custody, 1(4), 77-89.

Johnston, J. R., Walters, M. G., \& Olesen, N. W. (2005). Is it alienating parenting, role reversal or child abuse? A study of children's rejection of a parent in child custody disputes. J. Emotional Abuse, 5(4), 191-218.

Kelly, J. B., \& Johnston, J. R. (2001). The alienated child: A reformulation of Parental Alienation Syndrome. Family Court Review, 39(3), 249-266.

Kelly, J. B., \& Johnson, M. P. (2008). Differentiation among types of intimate partner violence: Research update and implications for interventions. Family Court Review, 46(3), 476-499.

Kendall-Tackett, K., Williams, L. M., \& Finkelhor, D. (1993). Impact of sexual abuse on children: A review and synthesis of recent empirical studies. Psychological Bulletin, 113, 164-180.

$L v . L$, (2002) (on file with author).

Leadership Council on Interpersonal Violence and Child Abuse, Dec. 16, 2009. http://www.leadershipcouncil.org/1/pas/DVP.html

Lesher, M., \& Neustein, A. (2005). From madness to Mutiny: Why mothers are running from the family courts - and what can be done about it. Lebanon, NH: Northeastern University Press.

Lewis, M. (2009). Home game: An accidental guide to fatberbood. New York, NY: Norton \& Co.

Lyons, T. D. (1998-1999). The new wave in children's suggestibility research: A critique. Cornell L. Rev., 84, 1004-1087.

$M v . M,(2010)$ (on file with author, under seal).

$M D v . A B$, (2008) (on file with author).

Maccoby, E. E., \& Mnookin, R. H. (1992). Dividing the child: Social and legal dilemmas of custody. Cambridge, MA: Harvard University Press.

Mahoney, M. (1991). Legal images of battered women: Understanding separation assault. Michigan Law Review, 90, 1-94.

Meier, J. (2003). Domestic violence, child custody and child protection: Understanding judicial resistance and imagining the solutions. American University Joumal of Law, Gender \& Social Policy, 11, 657-731.

Meier, J. (2009). A historical perspective on Parental Alienation Syndrome and parental alienation. Joumal of Child Custody, 6, 232-257.

National Council of Juvenile \& Family Court Judges. (1994). Model code on domestic violence. Available at http://www.ncjfcj.org/images/stories/dept/fvd/pdf/ modecode_fin_printable.pdf

O v. O, (2008-2009) (on file with author). 
Petition in Accordance with Inter-American Commission on Human Rights (2007). http://www.stopfamilyviolence.org/info/custody-abuse/legal-documents/ petition-to-inter-american-commission-on-human-rights/full-text-of-iachr-petition

Radford, L., \& Hester, M. (2006). Motbering through domestic violence. London/ Philadelphia: Jessica Kingsley Publisher.

Ragland, E. R., \& Fields, H. (2003). Parental Alienation Syndrome: What professionals need to know. American Prosecutors Researcb Institute and National District Attorneys Association, Update Newsletter, 16(6-7).

Sack, E. J. (2004). Battered women and the state: The struggle for the future of domestic violence policy. Wisconsin Law Review, 6, 1657-1740.

Smith, R., \& Coukos, P. (1997). Fairness and accuracy in evaluations of domestic violence and child abuse in custody determinations. The Judges' Journal, $38,30-56$.

Stark, E. (2007). Coercive control. New York: Oxford University Press.

Stark, E. (2009). Rethinking custody evaluation in cases involving domestic violence. Journal of Child Custody, 6, 287-321.

Sullivan, C. M., Nguyen, H., Allen, N., Bybee, D., \& Juras, J. (2000). Beyond searching for deficits: Evidence that physically and emotionally abused women are nurturing parents. Joumal of Emotional Abuse, 2(1), 51-71.

Waldman, A. (2010). Bad motber: A chronicle of maternal crimes, minor calamities, and occasional moments of grace. New York, NY: Anchor Books.

Wallerstein, J. S., Lewis, J. M., \& Blakeslee, S. (2000). The unexpected legacy of divorce-A 25 year landmark study. New York, NY: Hyperion Books.

$W v . F$, (2007) (on file with author).

Weithorn, L. A. (2001). Protecting children from exposure to domestic violence: The use and abuse of child maltreatment. Hastings Law Joumal, 53, 1.156.

Wilkins v. Ferguson, 928 A.2d 655 (D.C. App. 2007). 
